\title{
Author Correction: Emotional faces influence evaluation of natural and transformed food
}

\author{
Valerio Manippa $^{1}$ ([) Caterina Padulo $^{2} \cdot$ Alfredo Brancucci $^{2}$
}

Published online: 12 October 2017

(C) Springer-Verlag GmbH Germany 2017

\section{Author Correction: Psychological Research DOI 10.1007/s00426-017-0857-7}

This article unfortunately contained two mistakes.

In Table 1, the correct mean value of the Real Calorie of Transformed Food is " 363 " and not " 115 " as written in the published article (last row, last column). The correct Table 1 is now presented.
In the "Results" section of the Experiment 2, subheading "Reaction Times", in the first sentence Table 2 is mistakenly cited instead of Table 3 .

The authors sincerely apologize for their mistakes and for any inconvenience caused.
Table 1 Means (M) and standard errors (SE) of the main variables of our food stimuli category taken from the FRIDa (Foroni et al., 2013)

\begin{tabular}{|c|c|c|c|c|c|c|}
\hline & $\begin{array}{l}\text { Valence } \\
M( \pm \text { SE })\end{array}$ & $\begin{array}{l}\text { Familiarity } \\
M( \pm \text { SE })\end{array}$ & $\begin{array}{l}\text { Ambiguity } \\
M( \pm \text { SE })\end{array}$ & $\begin{array}{l}\text { Salience } \\
M( \pm \text { SE })\end{array}$ & $\begin{array}{l}\text { P. Calorie } \\
M( \pm \text { SE })\end{array}$ & $\begin{array}{l}\text { R. Calorie } \\
\mathrm{M}( \pm \mathrm{SE})\end{array}$ \\
\hline UplFd $(n=36)$ & $5.2(0.4)$ & $11.2(0.9)$ & $47.6(3.7)$ & $25.9(1.4)$ & $22.4(2.4)$ & 89 (16.7) \\
\hline $\operatorname{PlFd}(n=36)$ & $78.9(1.8)$ & $66.6(2.2)$ & $6.1(0.9)$ & $49.6(1.4)$ & $48.8(2.4)$ & $214.5(30.7)$ \\
\hline $\operatorname{NaFd}(n=18)$ & $78.5(2.9)$ & $68.1(3.3)$ & $5.5(1.1)$ & $40.9(2.7)$ & $19.5(3.5)$ & $66(23.3)$ \\
\hline $\operatorname{TrFd}(n=18)$ & $79.2(2.2)$ & $63.2(2.9)$ & $6.8(1.6)$ & $58.4(1.8)$ & $78.2(3.3)$ & $363(27.1)$ \\
\hline
\end{tabular}

The online version of the original article can be found under doi:10.1007/s00426-017-0857-7.

Valerio Manippa

valerio.manippa@unich.it

1 Department of Neuroscience, Imaging and Clinical Sciences,

"G. d'Annunzio" University of Chieti-Pescara, Via dei

Vestini, 29 - Blocco A, 66013 Chieti, Italy

2 Department of Psychological sciences, Health and the

Territory, "G. d'Annunzio" University of Chieti-Pescara,

Chieti, Italy 